\title{
Social Anxiety and Internet Addiction: CBT Intervention Module Development Based on Self-Reflection
}

\author{
Ayu Pradani Sugiyanto Putri ${ }^{\mathrm{a}}$, Elizabeth Kristi Poerwandari ${ }^{\mathrm{b}}{ }^{*}$, and Erida Rusli ${ }^{\mathrm{b}}$ \\ ${ }^{a}$ Clinical Adult Magister-Profession, Faculty of Psychology, Universitas Indonesia, Depok, \\ Indonesia; ${ }^{b}$ Clinical Psychology Department, Faculty of Psychology, Universitas Indonesia, \\ Depok, Indonesia. \\ *Corresponding Author: \\ Elizabeth Kristi Poerwandari \\ Clinical Psychology Department \\ Faculty of Psychology, Universitas Indonesia \\ Jl. Lkr. Kampus Raya, Depok, Jawa Barat \\ Indonesia, 16424 \\ Tel.: +62 217270004 \\ Email address: elizabeth.kristi@ui.ac.id
}




\title{
Social Anxiety and Internet Addiction: CBT Intervention Module Development Based on Self-Reflection
}

\begin{abstract}
This study presents an intervention module development based on the self-reflection of the first author, who has been experiencing social anxiety and Internet addiction. Said author has also been experiencing fear of negative evaluation and has negative beliefs about her ability to perform appropriately in social situations. Internet addiction has become her safe haven from social anxiety, allowing her to avoid anxiety from interactions with others and escape from her problems by engaging in more pleasurable activities derived from Internet use. Internet addiction provides gratification, including comfortable feeling and fulfillment of social relationship needs online. Based on the autoethnography as needs assessment, combined with the literature review, the authorwho is specializing in clinical psychology-proposes an intervention module. Her selfawareness about her problems and its negative consequences motivated her to monitor her behavior. She also realized the importance of helping others undergoing similar or even worse problems. The cognitive behavioral therapy (CBT) intervention module includes the following: (1) psychoeducation about social anxiety and Internet addiction,

(2) behavior modification to control excessive Internet consumption, (3) cognitive restructuring, and (4) exposure/assignment to develop social skills. After undergoing the intervention module, the first author showed a decline in Internet addiction and social anxiety. After that, three participants who also underwent intervention also showed a decrease in Internet addiction and social anxiety after six sessions. This article contributes to the literature by explaining Internet addiction and intervention from the perspective of someone who overcame the problems of social anxiety and Internet addiction after undergoing the proposed intervention.
\end{abstract}

Keywords: Internet addiction, intervention, social anxiety, social networking sites addiction, therapy

\section{Introduction}

The Internet is an integral part of human life. Social networking sites (SNS) comprise one of the most popular Internet contents. Someone with social anxiety can gain benefits from using SNS as it is driven by the fulfillment of the needs of belonging and self-presentation (Nadkarni \& Hofmann as cited in Casale \& Fioravanti, 2015). Social anxiety is a dysfunctional belief, in which the individual perceives that he/she will be negatively evaluated by others, thus making him/her consider social situations as threatening situations (Clark \& Wells, 1995). Therefore, such an individual often has unrealistically high standards toward oneself whenever he/she is interacting with others (Clark \& Wells, 1995).

Someone with social anxiety turns to SNS to help him/her fulfill the need of self-disclosure while in a relationship with others (Weidman et al., 2012). Through SNS, they can control and 
prepare things they can "present" to others (Lee \& Stapinski, 2012) as well as hide their expression and physical appearance from others (Young \& Lo, 2012). They believe SNS can minimize the negative evaluations of other people. Interacting through SNS provides reinforcements that, in turn, motivate an individual to repeat the behavior and gain the same reinforcements (Davis, 2001).

The above process can lead to Internet addiction (Davis, 2001). Internet addiction or pathological Internet use that is uncontrolled and problematic, thus causing negative consequences (Young, 2009). A past study has proven that there exists a direct link between social anxiety and problematic Internet usage (Casale, 2015). Social anxiety is also confirmed as a significant predictor of problematic Internet usage when controlling depression and anxiety problem (Lee \& Stapinski, 2012).

The excessive use of the Internet provides only superficial benefits. Lee and Stapinski (2012) argue that online contact actually encourages a person to avoid face-to-face interaction. Some people tend to feel that their online life is better than what they have in the real world, assuming their social skills are increasing (Lee \& Stapinski, 2012), and feel success in establishing relationships using SNS (Shalom et al., 2015). Actually, the excessive Internet usage of individuals with social anxiety leads to low levels of life satisfaction and self-esteem and high level of depression (Weidman et al., 2012). This is because their efforts to compensate for their inability to interact with others ultimately fail to improve their well-being. The Internet can also actually lead its users to further loneliness, withdrawal from their social environments, and restrictions in genuine social relationships (Wolfradt \& Doll as cited in Mazalin \& Moore, 2004; Kuss \& Griffiths, 2011).

The authors of the present study have yet to find a module of intervention to resolve Internet addiction (particularly addiction to SNS) caused by social anxiety. Hence, this study aims to develop a specific module that can be used as an intervention to help resolve Internet addiction caused by social anxiety. This module combines the first author's autoethnography and selfreflection as needs assessment, the literature review about Internet addiction, social anxiety, and the relevant interventions.

\section{Methods}

\section{Participant 1 (Self-reflection)}

This study was based on the social anxiety and Internet addiction experienced by the first author (female, 25 years old). She is a master's degree student majoring in clinical adult psychology. Her background made her more adequate to monitor her behavior and know what method would be more effective to overcome social anxiety and Internet addiction. The other two authors are her supervisors tasked to supervise and strengthen objectivity in problem analysis and development of the intervention module. Based on the first author's experience and the literature 
review, the authors proposed an intervention module to overcome Internet addiction-especially SNS addiction-caused by social anxiety.

\section{Second Set of Participants (Intervention Module Trial)}

Once developed, the intervention module was tested on participants who met the following inclusion criteria: (a) undergraduate student of Universitas Indonesia, (b) preferred to interact by using SNS rather than face-to-face interactions, (c) a score of above 49 in the Internet Addiction Test (Young, 1998), (d) a measurement score of above or equal to 34 in the Social Interaction Anxiety Scale (Mattick \& Clarke, 1998), and (e) willing to undergo the intervention by filling out the informed consent provided by the authors.

The intervention program lasted for six weeks and consisted of one pre-session and five main sessions. Cognitive behavioral therapy (CBT) intervention sessions were conducted individually. Each session was scheduled with a one-week break and each session lasted for \pm 2 hours. Two weeks after the last session, the authors conducted a follow-up to determine whether the participants showed any changes after following the intervention module.

\section{Research Design}

This study used the autoethnography method as the basis of the needs assessment for designing the intervention module. Autoethnography is a qualitative research in nature, and autobiographical writing can help researchers explore an individual's unique life experiences in relation to social and cultural institutions (Custer, 2014). This method of research involves selfobservation and reflective investigation (Marechal, as cited in Chang, 2011). The type of autoethnography used in this work is analytic autoethnography, which focuses on developing theoretical explanations of broader social phenomena (Chang, 2011). In addition to selfreflection, the authors also conducted a literature review to analyze the experiences recorded and develop the intervention module.

The module was then tested in three participants to check its effectiveness in reducing Internet addiction and social anxiety.

\section{Results}

\section{The Case (Self-Narratives of the First Author)}

\section{Social Anxiety}

Ever since my teens, I realized that speaking in front of people or being the center of attention made me worried. It was hard for me to express what I was thinking or feeling in good sentences. I was always afraid that people would not understand what I was talking about. I was afraid that people could see my weaknesses. I chose to stay silent even though I had something in my mind. I only focused on worrying about the things that people would think about me. I was terrified that people would think that my ideas were silly and dumb. I also felt that my opinion was lacking and can be considered nothing compared to others. 
Whenever I needed to talk in front of people or be the center of attention, my heart beat faster; I could feel butterflies in my stomach, and I feel my body heat rise while sweating. My prediction came true whenever I talked. I could never talk with good, well composed sentences even though I had already prepared for it beforehand. Hence, I chose to speak fast to make people stop paying attention to me. People often asked me what I meant with my statement. This was a proof that I really could not talk well with people. After I stated something, I immediately regret what I had said. I believed that I had to be more careful about what I was going to say in the future in order to not repeat the same mistake over again.

\section{"Safety Behavior" to Prevent Social Anxiety}

I always opened some apps on my phone whenever I was with my friend. By opening those apps on my phone, I made others think that I was busy so it would divert their attention from me and would not try to talk to me. I also felt more comfortable because doing so also diverted my worries.

Compared to having a face-to-face conversation, I preferred to talk using SNS applications. In SNS, I could always prepare what I needed to say to others so that they could understand what I would like to talk about. It was also because others could not see me stiffen up and confused while preparing what I wanted to say. After I finished writing something, I re-read my message again to make sure that others would be able to understand and that there would be no mistake in it.

Whenever I wanted to express my thoughts, I choose to use SNS because I believed that it was the better way to ensure that my thoughts would be heard and responded to by others. I thought that I could express my opinions better by using SNS. I also believed that I knew people better if I had conversations with them through SNS apps. When I receive news about my friends from SNS, I always felt that I knew them better. If someone commented on one of my posts, I felt that I was close to him/her even if, in reality, I seldom interacted with them. I believed that by using SNS I could be the real me because I could express my thoughts to others clearly. It was also by using SNS that I could have relations that I wanted to have with others.

\section{Internet Addiction}

I always planned ahead to open my SNS accounts and what to post there whenever I was offline. I did that because I wanted to make my posts as interesting as possible so that people would be willing to comment on them. I also double-checked and edited my drafts before I finally posted them.

I always checked my SNS accounts to see new updates or if there was someone that tried to contact me. An interval of 5-10 minutes of not accessing SNS to see recent feeds made me anxious. Even if there was no new notification, I always refreshed my Internet connection to make sure that I did not miss any messages. I was always worried that I would miss new updates from my friends. 
The first thing that I needed to do before sleeping and after waking up was to check my SNS feeds. I would make sure that there was no single information that I missed. The feeling of being worried that I would miss the newest information always came to me whenever I did something that was unrelated to the Internet and mobile apps. My hands automatically accessed all my SNS accounts and other Internet apps even though I was currently working on other tasks. I could not handle my desire to open these apps and it resulted in spending longer time on those apps than I meant to.

Even until now, especially when I am alone, whenever I have problems or working on something difficult, I choose to open my Internet apps, especially the SNS apps. Accessing my SNS accounts can help me forget all the problems and negative thoughts in me. I feel that by using other Internet apps, it can give the same exact happy feeling.

\section{Effect}

The effect that I felt from being an SNS apps addict was that it disturbed my real social life and my academic life. I felt that I did not really have real social relationships with people. I couldn't create real and proper relationships with others. In fact, SNS could not help fulfill the benefits of a real social relationship and was only a temporary solution to fill my social needs. I felt helpless because I thought there were no other things that I could do other than using SNS apps and the Internet. The numbers of apps that I had to check every day kept increasing and were disturbing my life. Sometimes, until now, it affects my schedule to the point that my work has piled up just because I can't focus on what I should do, and instead, I prefer to spend my time on the Internet. Nevertheless, my Internet addiction right now is much less than ever before.

\section{The Severity of the Situation}

I first experienced social anxiety before experiencing difficulties in controlling my Internet use. Meanwhile, even though I was able to interact with others, I still felt that my Internet usage, especially on SNS, was still not decreasing. I thought that I could not stop using the Internet and this would be a real problem for me if I could not limit this habit. My inability to control my Internet usage worsened since I started living away from my family to pursue my education and started living in a new environment. Whenever I had a problem or if there was something that I did not think I could handle myself, it was even harder to control myself from using the Internet, which only increased my time in using the Internet aimlessly. Whenever I was feeling lonely and there was no one to support me, again, the time I spent on SNS increased.

\section{Conceptual Analysis of the Case}

From the experience of the first author, the authors can conclude that she experienced social anxiety. This conclusion was supported by her score of 67 in the social anxiety test (Social Interaction Anxiety Scale Test, Mattick \& Clarke, 1998). Social situations triggered her negative assumptions about her own performance and how others would see her. This corresponds with the finding of Clark and Wells (1995), who argued that someone with a social anxiety has 
dysfunctional beliefs, such as an overall senses of negativity and unrealistically high standards when interacting with others, believing that they would have negative evaluations from others.

A dysfunctional belief of having a high standard that must be met makes someone who has social anxiety think that he/she has to reach the perfect one, whereas in reality, this could be an impossible goal. In the case of the first author, this has led to her feeling of inability because she could not even reach her own standard. Meanwhile, her dysfunctional belief about getting negative evaluation from others made her think that the social environment was a threatening one. This apprehension was the reason why she was more focused on her worries whenever she was having a conversation with others. She could not focus on the things she wanted to say, and in turn, this worsened her inability to convey what she really wanted to express. This anxiety also triggered physiological responses, such as increasing heartbeat, stomach ache, rising body heat, and sweating. Whenever she tried to speak fast, this only resulted in her inability to control her tone and expression. Others would ask her to repeat what she just said. Her worries and physiological behaviors as well as others' responses reinforce her dysfunctional belief on how bad her performance was. She ignored others' positive appreciation and took that as a coincidence. Due to this seemingly vicious cycle, the subject could never change the belief that she always performed badly in front of people.

The first author chose to anticipate a repeated mistake by doing other things that could keep her away from the possibility of making the same mistake. She pretended to play with her phone and opened a mobile app whenever she was with someone. This kind of behavior, called "safety behavior," did not allow her to confirm her dysfunctional belief and it has remained that way prior to the intervention.

According to Davis (2001), who proposes a cognitive-behavioral model of pathological Internet use, psychopathology, such as social anxiety, is a distal cause that can trigger problematic Internet addiction. Whenever an individual interacts with people and feels worried about others' view, phone and Internet usage can give that person a feeling of comfort and allows him/her to divert his/her worries.

Someone who is addicted to SNS also chooses to interact with people using SNS as a safety behavior to prevent repeating the same mistake. In the case of our main subject, she felt that she obtained benefits from interacting with others via the SNS. She was able to control what she was going to say and show to others; thus, the chance of being negatively evaluated by others was reduced when she communicated online (Lee \& Stapinski, 2012). Communicating via SNS is a safety behavior that allows a person with social anxiety to interact with others while minimizing the potential threats and worries (Shepherd \& Edelmann, 2005). SNS also fulfills the need to interact with others in an individual with social anxiety, especially as it gives a feeling of being connected with others and a sense of belonging (Shepherd \& Edelamnn, 2005). An individual 
with social anxiety would also feel that his/her social skills would increase because of SNS use (Lee \& Stapinski, 2012).

The benefits gained from the SNS use serve as a positive reinforcement because they can help one overcome social anxiety. A person gains reinforcement in several ways, such as the feeling of comfort in the absence of social anxiety, the feeling of having friends, and the ability to have good relationships with others. Unfortunately, prolonged SNS use, although considered a safety behavior, makes a person unable to prove one's distorted thoughts, resulting in deeper distortion.

Internet addicts also have the same feeling whenever they do anything online-related. Other online activities could act as diversions from anxiety whenever a person faces a problem. This positive feeling is the secondary reinforcement that motivates a person to repeatedly resort to online activities, ultimately leading to problematic Internet use or even Internet addiction (Davis, 2001).

Some studies have shown that social anxiety is related to Internet addiction. Casale (2015) suggests a direct link between social anxiety and problematic Internet usage. Social anxiety has also been confirmed as a significant predictor of problematic Internet usage when controlling depression and worries (Lee \& Stapinski, 2012). According to the research review done by Prizant-Passal, Shechner, and Aderka (2016), who examined the relation between social anxiety and problematic Internet usage, there is a positive correlation between the two variables and individuals experience a feeling of comfort whenever they are online.

Davis (2001) suggests that a maladaptive or distorted cognition is the proximal cause of Internet addiction. This cognitive distortion is represented by the belief that the Internet can help fulfill one's social needs and that there is no better way to communicate with people other than using the Internet. Such a belief is due to social anxiety and a helpless feeling of not having the Internet. This all-or-nothing thought is a maladaptive cognitive distortion that causes Internet addiction (Davis, 2001). After realizing that her Internet usage was problematic, the subject of the current study felt upset with her uncontrolled need to use the Internet. In turn, this led to an uncomfortable feeling and, paradoxically, she then used the Internet to reduce that uncomfortable feeling because she was sure that the Internet can help reduce it.

The type of Internet addiction that the first author possesses is classified as SNS addiction. According to the criteria of Internet addiction from Beard and Wolf (2001), the first author met 7 out of 8 criteria of an Internet addict: preoccupied with the Internet (plans to have an online activity and is anticipating for the next online activity session); the need to increase the duration of using the Internet to achieve a feeling of satisfaction; fails to control, limit or stop the use of the Internet; being restless and upset when trying to reduce or limit the use of the Internet; has longer online sessions than expected; significant risk of losing the chance to have real, face-toface relations and academic roles because of the Internet; and uses the Internet as an escape from one's problems or as a medium to reduce one's feeling of helplessness and worries. The first 
author's SNS addiction was also proven by her score of 77 in the Internet Addiction Test (Young, 1998), which indicated moderate Internet addiction.

The excessive use of SNS has prevented the main subject from realizing the seriousness of her social anxiety while simultaneously pushing her further from real life social interactions. With the close linkage between social anxiety and Internet addiction, an intervention that treats both problems is thus needed. This is because it is not enough to treat social anxiety and expect that this will automatically help an individual overcome her Internet addiction. Meanwhile, overcoming Internet addiction without addressing social anxiety might lead an individual to relapse into her Internet addiction as the root problem (i.e., being anxious to face real life social encounters) is not properly addressed and solved.

\section{Module Development: Intervention for Social Anxiety and Internet Addiction}

The effectiveness of using CBT in resolving Internet addiction has been proven by a number of studies done by Young $(2007,2013,2014)$ and Khazaal et al. (2012). A journal review about CBT on Internet and video games addiction finds at least 23 studies using CBT as a therapy for such addiction with satisfactory results (Lemos, Abreu, \& Sougey, 2014). According to a literature review done by Gil, Carillo, and Meca (2001), CBT intervention is also proven effective in overcoming social anxiety. This intervention design is develop based on CBT-IA, originally designed by Young (2007) and De Abreu and Goes (2011), which is for general Internet addiction, and CBT from Hope et al. (2000), which is for social anxietyan intervention module to resolve Internet addiction, particularly SNS addiction caused by social anxiety.

The goal of this study, therefore, is to develop an intervention aimed at reducing both social anxiety and Internet addiction simultaneously. This is because if we only target Internet addiction without solving its root case, it would be possible for the person to relapse because the need for social relationships remains unfulfilled.

The role of the therapist is to help the addicted person view his/her problem objectively and control the progress of the intervention. It is very important for the client to understand the purpose of each step of the intervention so that he/she is more motivated to complete the process.

The first session is the provision of psychoeducation about different related issues, such as the what, why, and how of social anxiety; Internet addiction; and the relation between social anxiety and Internet addiction. This is based on the assumption that the knowledge about social anxiety and Internet addiction can help clients comprehend themselves better, including the causes of the problems they encounter. The individuals can also know the important parts they must observe concerning their thoughts and behaviors. Meanwhile, they will also be more convinced about the negative impact of the problematic behavior when exposed to evidence-based information. It is also important to allow the clients to comprehend the cycle of Internet addiction-by understanding the cycle, they will be more aware of any event that can worsen their problem. The SNS addicts also need to know the long-term negative effects of Internet addiction and 
social anxiety. This can motivate them to resolve Internet addiction. Internet and SNS addicts initially act defensively, claiming that the usage is problematic, but still they prefer the temporary positive impact of the usage. It is easier for those with social anxiety to acknowledge their social anxiety than to acknowledge that they are trapped in SNS addiction.

After the psychoeducation, the next session is behavior modification. From a CBT therapy session for an Internet addict compiled by Young (2014), the first step to resolve Internet addiction is behavior modification. Behavior modification on CBT aims to control the usage of Internet step by step by reducing the length of time an individual spends online. In the case involving the first author, it is most effective for her to delete the applications and turn off the Internet connection to enable her to reduce her SNS usage. When her hand started to grab her phone and then she realized that the applications were already deleted, she also realized her thoughts and the need to control her behavior. She was also able to better realize her worries compared to the situation wherein she was unable to do anything to limit her SNS usage.

A written reminder makes it easier for a person to stop when he/she is going to open an application and also helps limit its usage. Senormanci, Konkan, and Sungur (2012) also support this statement. A reminder card may help the client reduce Internet usage. A clear written schedule indicating how much time a person should devote to Internet use and a target to reach a certain point on work that he/she needs to finish also helps strengthen the commitment to limit the daily usage of the SNS. A support and external control from another person, especially a therapist, is also needed. For an adult client, actively discussing with him/her what method to use is important to increase the client's motivation to solve his/her problem. Clients and therapists should also discuss other activities that can replace the Internet. Interacting with others in a comfortable social situation can be an alternative that can replace Internet-based activities.

Based on the first author's experience, social anxiety can be reduced by exposing herself to have social interactions with people. The hypothesis is that exposure is more effective as the first step of the intervention as the client might see directly what his/her worries are. However, the clients must be prepared first. Therefore, teaching clients beforehand about the ability to change their focus to the external circumstances, to stay relaxed (breath relaxation), and to understand how they can develop social relationships is important. In this way, clients are expected to understand themselves better and simultaneously accomplish their assignment to reduce worries.

Given that behavior modification can lead clients to develop insights that dispel their initial beliefs, the next session is cognitive restructuring. Cognitive restructuring is also needed to make the clients realize their problems more comprehensively. When they control their Internet use, they are asked to write down the immediate thoughts that come up before and after they control their behavior. They will also need to write down their immediate thoughts when interacting with other people. With this, the clients and therapist discuss the cognitive distortions that strengthen their need to use the Internet and cause their social anxiety. The therapist also needs to change 
the belief of the clients that SNS can fulfill their social needs. This is easier to do when the clients already know and have proof that their worries are, indeed, the problem. It is common for people who have cognitive distortion to think that a positive thing that happened to them is just a coincidence and not because of their behavior. Writing down the facts that are the opposite of the person's belief and putting them somewhere visible is effective in helping individuals develop and hold on to new beliefs and perceptions of themselves. This repetitive application of behavior modification is important in strengthening the positive belief that someone needs to have to reduce his/her problems.

After having new adaptive beliefs, clients are expected to practice. Therefore, they need to be exposed to real assignments. This exposure can strengthen new beliefs while simultaneously strengthening concrete skills to control one's own behavior. The therapist needs to ask the clients to identify anything that can trigger the repetition of social anxiety and Internet addiction as well as the alternative behaviors that might prevent such a repetition (Khazaal et al., 2012). Then, to motivate them to maintain their new behaviors and beliefs, the clients need to be reminded about the benefits they gained when they succeeded in changing their behaviors (Khazaal et al., 2012).

\section{The Effectiveness of the Intervention Module}

After implementing this intervention module to herself, the first author showed a decrease in Internet addiction (using Internet Addiction Test, Young, 1998) and in social anxiety (using Social Interaction Anxiety Scale, Mattick \& Clarke, 1998). Below is a table containing a comparison of her scores before and after applying this intervention module.

Table 1

Comparison between the first author's pre-test and post-test scores in the Internet Addiction Test

\begin{tabular}{ccc}
\hline & Pre-test score & Post-test score \\
\hline Internet Addiction Test & 77 & 20 \\
\hline Social Interaction Anxiety Scale & 67 & 36 \\
\hline
\end{tabular}

Based on the selection of participants, five participants also took part in the intervention. They were all female undergraduate students, aged between 19-22 years old. Of the five participants, only three completed the entire series of intervention programs. The other two did not participate until the end. Nonetheless, this intervention module proved to be effective in reducing Internet addiction rates among the three participants (Putri, 2018) as presented in Tables 2 and 3.

Table 2

Comparison among the pre-test, post-test, and follow-up scores in the Internet Addiction Test

\begin{tabular}{lccc}
\hline & Pre-test score & Post-test score & Follow-up score \\
\hline Participant 1 & 89 & 34 & 16 \\
Participant 2 & 95 & 42 & 43 \\
Participant 3 & 69 & 11 & 8 \\
\hline
\end{tabular}


Table 3

Comparison among the pre-test, post-test, and follow-up Social Interaction Anxiety Scale score

\begin{tabular}{cccc}
\hline & Pre-test score & Post-test score & Follow-up score \\
\hline Participant 1 & 79 & 64 & 42 \\
Participant 2 & 96 & 60 & 65 \\
Participant 3 & 82 & 35 & 24 \\
\hline
\end{tabular}

After following the intervention activities based on the module, there was a proven decrease in the scores of the social anxiety and Internet addiction measures, especially in the type of social network addiction, in all participants (Putri, 2018). All the participants who previously experienced Internet addiction are now in the category of average Internet users after following the intervention activities. We also found that the decrease in social anxiety affected the decrease in the level of social network addiction. The participants realized that they initially used SNS to fulfill unmet needs in the real world (Young, 2013). As their social needs are met in the real world and the participants perceived comfort in real life social situations, they no longer felt the urge to meet their social needs from SNS (Putri, 2018). This is in accordance with statements from Casale and Fioravanti (2015), who reported that social anxiety has a direct impact on social networking addiction.

\section{Discussion}

The excessive use of Internet, especially SNS, is a safety behavior used by others to avoid social contact and to cope with social anxiety. This leads to the repetition of Internet usage and addiction and increased maladaptive thoughts. With social anxiety as the core problem, this should be treated first to enable individuals to reduce their Internet addiction. Hence, in order to handle two issues simultaneously, there are several steps to undertake: psychoeducation, behavior modification, cognitive restructuring, and exposure. This research has shown that the intervention module based on the personal experience of the first author reduced Internet addiction and social anxiety in both the first author and the three other participants.

This article contributes to the literature by explaining the development of an intervention based on the needs assessment through the autoethnography method. Internet addiction and its main cause was also examined from the point of view of someone who has experienced it. Future studies should investigate and evaluate the effectiveness of the treatment in decreasing Internet addiction and social anxiety in a larger population. 


\section{References}

Beard, K. W., \& Wolf, E. M. (2001). Modification in the proposed diagnostic criteria for internet addiction. Cyberpsychology \& Behavior, 377-383. doi:10.1089/109493101300210286

Casale, S., \& Fioravanti, G. (2015). Satisfying needs through social networking sites: A pathway towards problematic Internet use for socially anxious people? Addictive Behaviors Reports, 34-39. doi:10.1016/j.abrep.2015.03.008

Chang, H. (2011). Autoethnography as methods. California: Left Coast Press.

Clark, D. M., \& Wells, A. (1995). A cognitive model of social phobia. In R. G. Heimberg, M. R. Liebowitz, D. A. Hope, \& F. R. Schneier (Eds.), Social Phobia: Diagnosis, Assessment, and Treatment (pp. 69-93). New York, NY: The Guilford Press.

Custer, D. (2014). Autoethnograpy as a transformative research methods. The Qualitative Report, 19, 1-13. Retrieved from http://www.nova.edu/ssss/QR/QR19/custer21.pdf

Davis, R. A. (2001). A cognitive-behavioral model of pathological internet use. Computers in Human Behavior, 187-195. doi:10.1016/S0747-5632(00)00041-8

De Abreu, C. N., \& Goes, D. S. (2011). Psychotherapy for internet addiction. In K. S. Young, \& C. N. De Abreu (Eds.), Internet addiction: A handbook and guide to evaluation and treatment (pp. 155-173). Hoboken, NJ: John Wiley \& Sons, Inc. doi: 10.1002/9781118013991.ch9

Gil, P. J., Carrillo, X. M., \& Meca, J. S. (2001). Effectiveness of cognitive-behavioural treatment in social phobia: A metaanalytic review. Psychology in Spain, 5. No 1, 17-28.

Hope, D. A., Heimberg, R. G., Juster, R. H., \& Turk, C. L. (2000). Managing social anxiety a cognitive: Behavioral therapy approach-client workbook. Colorado, CO: Graywind Publications Incorporated.

Khazaal, Y., Xirossavidou, C., Khan, R., Edel, Y., Zebouni, F., \& Zullino, D. (2012). Cognitive-behavioral treatments for "internet addiction". The Open Addiction Journal, 30-35. doi: 10.2174/1874941001205010030

Kuss, D. J., \& Griffiths, M. D. (2011). Online social networking and addiction: A review of the psychological literature. International Journal of Environmental Research and Public Health, 3528-3552. doi: 10.3390\%2Fijerph8093528

Lee, B. W., \& Stapinski, L. A. (2012). Seeking safety on the internet: Relationship between social anxiety and problematic internet use. Journal of Anxiety Disorders, 197-205. doi: 10.1016/j.janxdis.2011.11.001

Lemos, I. L., Abreu, C. N., \& Sougey, E. B. (2014). Internet and video game addictions: A cognitive behavioral approach. Rev Psiq Clín, 82-88. doi:10.1590/0101-60830000000016

Mattick, R. P., \& Clarke, J. C. (1998). Development and validation of measures of social phobia scrutiny fear and social interaction anxiety. Behaviour Research and Therapy, 36, 455-470. doi:10.1016/S0005-7967(97)10031-6

Mazalin, D., \& Moore, S. (2004). Internet use, identity development and social anxiety among young adults. Behaviour Change, 21, 90-102. doi: 10.1375/bech.21.2.90.55425

Prizant-Passal, S., Shechner, T., \& Aderka, I. M. (2016). Social anxiety and internet use: A meta-analysis: What do we know? What are we missing? Computers in Human Behavior, 62, 221-229. doi:10.1016/j.chb.2016.04.003

Putri, Ayu Pradani Sugiyanto. (2018). Cognitive-behavioral therapy (CBT) to reduce social networking sites addiction and social anxiety (Unpublished Thesis). Universitas Indonesia, Depok, Indonesia.

Senormanci, O., Konkan, R., \& Sungur, M. Z. (2012). Internet addiction and its cognitive behavioral therapy. In I. R. De Oliveira, Standard and Innovative Strategies in Cognitive Behavior Therapy (pp. 171-190). Rijeka: InTech. doi: $10.5772 / 26265$

Shalom, J. G., Israeli, H., Markovitzky, O., \& Lipsitz, J. D. (2015). Social anxiety and physiological arousal during computer mediated vs.face to face communication. Computers in Human Behavior, 44, 202-208. doi:10.1016/j.chb.2014.11.056

Shepherd, R.-M., \& Edelmann, R. J. (2005). Reasons for internet use and social anxiety. Personality and Individual Differences, 949-958. doi:10.1016/j.paid.2005.04.001

Weidman, A. C., Fernandez, K. C., Levinson, C. A., Augustine, A. A., Larsen, R. J., \& Rodebaugh, T. L. (2012). Compensatory internet use among individuals higher in social anxiety and its implications for well-being. Personality and Individual Differences, 53, 191-195. doi:10.1016\%2Fj.paid.2012.03.003

Young, C. M., \& Lo, B. C. (2012). Cognitive appraisal mediating relationship between social anxiety and internet communication in adolescents. Personality and Individual Differences, 78-83. doi:10.1016/j.paid.2011.09.001

Young, K. S. (1998). Internet addiction: The emergence of a new clinical disorder. CyberPsychology and Behavior, 1, No. 3., 237-244. doi:10.1089/cpb.1998.1.237

Young, K. S. (2007). Cognitive behavior therapy with internet addicts: Treatment outcomes and implications. Cyberpsychology and Behavior, 10, 671-679. doi:10.1089/cpb.2007.9971 
Young, K. (2009). Internet addiction: Diagnosis and treatment consideration. Journal Contemporary Psychotherapy, 241-246. doi:10.1007/s10879-009-9120-x

Young, K. S. (2013). Treatment outcomes using CBT-IA with internet-addicted patients. Journal of Behavioral Addictions, 209215. doi:10.1556\%2FJBA.2.2013.4.3

Young, K. S. (2014). CBT-IA: The first treatment model for internet addiction. Journal of Cognitive Psychotherapy: An International Quarterly, 304-312. doi:10.1891/0889-8391.25.4 